\title{
Multi-Dimensional Inversion of Airborne Total Magnetic Intensity Data at the West-of-Edfu Region, Upper Egypt
}

\author{
Ahmad H. M. Habeeb ${ }^{(2)}$, Karam. S. I. Farag ${ }^{(1)}$ and Ali M. S. Abdelaziz ${ }^{(2)}$ \\ (1) Geophysics Department, Faculty of Science, Ain Shams University, Abbassia 11566, Cairo, Egypt \\ ${ }^{(2)}$ Exploration Division, Nuclear Materials Authority (NMA), P.O. Box 530, Kattamyia Road, Maadi, Cairo, Egypt
}

\begin{abstract}
The acquired high-resolution airborne total magnetic intensity data over the West-of-Edfu region, within the southern Egyptian western desert, were consistently and extensively inverted in terms of two- and three-dimensional (2D/3D) magnetic susceptibility layered-earth models to accurately delineate the deep-seated basement structures and configuration. The starting models for all inversion trails were initially built-up using a-priori information gained from the progressive standard qualitative and semiqualitative interpretation results. The encountered deep-seated Precambrian basement structures are generally trending $N W-S E$ and $N E-S W$ directions. The depth-to-the-basement estimates were reliably varied between 0.13 and $4.75 \mathrm{~km}$, from the existing averaged ground surface, and correlated well with the available drilled stratigraphic-control wells. Additionally, the results suggested that the sedimentary cover is tectonically affected by such deep-seated basement structures with a set of tectonic faults extending from the basement upwards through the sedimentary cover. These faulted sedimentary blocks may constitute potential structural traps for the hydrocarbon accumulation.
\end{abstract}

Keywords: Two- and three-dimensional magnetic susceptibility layered-earth models, deep-sated basement structures, West-of-Edfu region, Upper Egypt.

\section{Introduction}

Aeromagnetic maps reflect spatially-varied anomalies of the earth magnetic field. These magnetic field variations are usually related to the distribution of subsurface magnetic susceptibility structures and/or remnant magnetization. Shallow-seated sedimentary rocks, in general, have low magnetic content compared with the deep-seated basement (igneous and metamorphic) rocks which tend to have a much greater magnetic content. Conventional semi-quantitative interpretational techniques, like local power spectra and analytical signal methods which are roughly used to estimate an averaged depth-to-the-basement and, indirectly, thickness of the sedimentary basin, can delineate such subsurface structures briefly. Alternatively, multidimensional inverse modeling (inversion) represents the up-to-date quantitative interpretational technique that can physically delineate both subsurface magnetic susceptibility structures and depth-to-the-basement from the observed aeromagnetic data either in spatial- or frequency-domain.

In applied aeromagnetics, the total magnetic intensity (TMI) data are measured as a result of the earth magnetic field. This is what we might call a 'forward problem'; a model is given and the data are calculated. The forward (direct) problem is always uniquely solvable. It is often the other way around; data have been measured and we wish to derive a reliable layered-earth model that is consistent with the data, what may be described as 'inverse problem' which is concerned with the problem of making magnetic susceptibility interfaces (layer boundaries) from the measured data. Since nearly all field data are subjected to some uncertainty, these interfaces are statistically dependent, and therefore no inverse problem in aeromagnetics is uniquely solvable, Due to such an invariable non-linearity between the measured data and desired model parameters (layer susceptibility and thicknesses), we usually use an iterative procedure in which the non-linear inverse problem is replaced, at each iteration, by its linearized approximation to be solved Throughout, the data and model parameter vectors are related via a non-linear response function, which tells us how to calculate the synthetic data from the given model. The overall goal of the inversion is then to minimize the deviation between the measured and calculated data, what may be described as the 'objective function.' To derive an iterative inversion scheme, the response function is linearized about a 
starting model (initial guess) by expanding it into a Taylor's series approximation and ignoring the higher terms. This is the classical 'Gauss-Newton' solution (Marqardt, 1963; Lines and Treitel, 1984; Webring1985) which can be applied successively to improve (refine) the initial model until an optimal model update is obtained in an appropriate least-squares fashion. The process iterates until a given convergence criterion or a maximum number of iterations is reached. To determine how well the model fits the measured data, the usual weighted least-squares criterion (Chi2 or root mean-square (RMS) misfit) is used, attempting generally at minimizing the familiar estimate.

This full non-linear least-squares optimization algorithms, like layered-earth inversion schemes, try to solve an over-determined geophysical inverse problem (i.e. when model parameters are far less than collected data points), and hence requires a starting model which has the desired (not more) number of layers. It modifies (adjusts) the layer susceptibility and thicknesses in the starting model iteratively to best fit the data at some tolerance, allowing incorporating a-priori information to constrain the solution a bit (Marquardt, 1963). The Layered-earth inversion was carried out for RTP data in frequency-domain.

\section{A-Prior Information and Geologic Setting}

West-of-Edfu region is located at the southern Egyptian western desert between latitudes $24^{\circ} 13^{\prime} 14^{\prime \prime}$ and $26^{\circ} 01^{\prime} 02^{\prime \prime} \mathrm{N}$, and longitudes $31^{\circ} 06^{\prime} 00^{\prime \prime}$ and $32^{\circ} 42^{\prime} 43^{\prime \prime} \mathrm{E}$ (Figure 1). It is stretched along the western blank of Lake Nasser and Nile River, and bounded from the west by Sin El-Kaddab plateau. The regional topography is uneven, elevation differences ranged between 298 and $508 \mathrm{~m}$ above sea level (Figure 2a). Geologically, West-of-Edfu region is situated within the African Platform with its Precambrian folded basement, and hence its tectonic framework is related to the Last African Orogenic belt (Said, 1962; Abd ElRazik and Razavaliaev, 1972). The Nile valley at such a region is mainly controlled by wrench faults that are generally parallel either to the Gulf-of-Suez or Gulf-of-Aqaba directions (Youssef, 1968). The region has been affected by the same structural deformation processes that generated the Nile Valley and shaped the Kom Ombo basin located west of the Nile River (Koch et. al., 2012). Structurally, it represents a relatively large basin (western extension of the Kom Ombo basin), consisting of a series of unconnected depressions (Attia, 1954; Said, 1962; FAO, 1966). It is dissected by NNW-SSE, NW-SE and E-W gravity faults rooted in the underlying Precambrian basement, developing alternating horst-graben structures (Salman, 1974).

The general stratigraphy of the region ranges in age from Precambrian (deep-seated basement rocks) to Tertiary (Paleocene/Eocene)-Quaternary (shallow-seated sedimentary rocks) (Figure 2b). Sedimentary cover comprises mainly carbonate rocks (alternating limestone, marl, shale with subsidiary chert and dolomite) and Nubian sandstone sequence (alternating sandstone, shale with subsidiary clay) (Issawi, 1983 and Issawi and McCauly, 1993; Centurion Petroleum Corp., 2007). Recently, two important productive oil fields have been discovered close to the region. In spite of this recent discovery, the hydrological setting of the region is still not well understood, and therefore, its groundwater potential remains largely unknown (Koch et. al., 2012). Nevertheless, deep-seated structural fashion at the West-of-Edfu region is not well-documented due to the rare of drilled stratigraphic-control wells and the lake of any other geophysical models within the basin. Therefore, conducting a deep-investigative potential-field survey, like high-resolution aeromagnetic, can help improve the resolution of the subsurface earth model. 


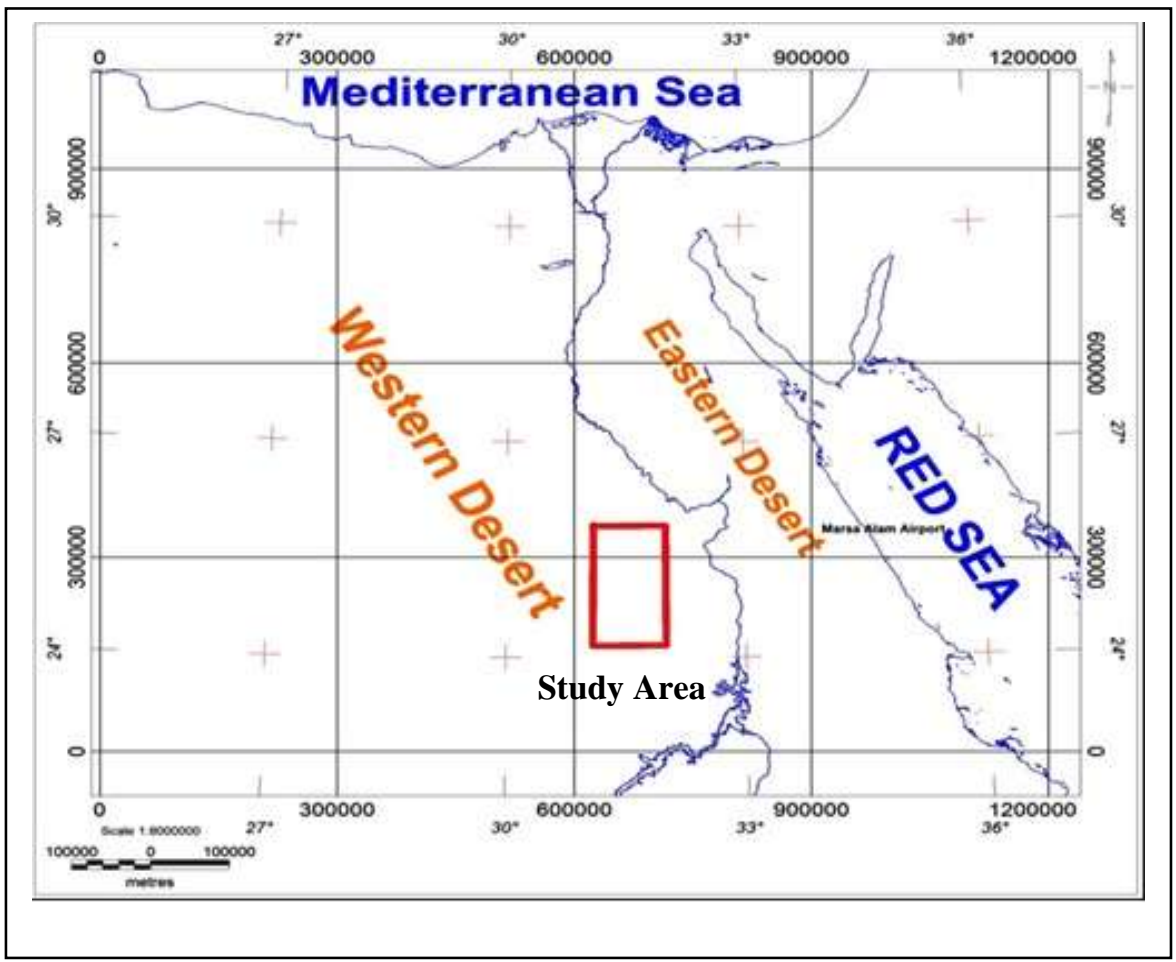

Figure 1: General location of the West-of-Edfu region within the southern Egyptian western desert.
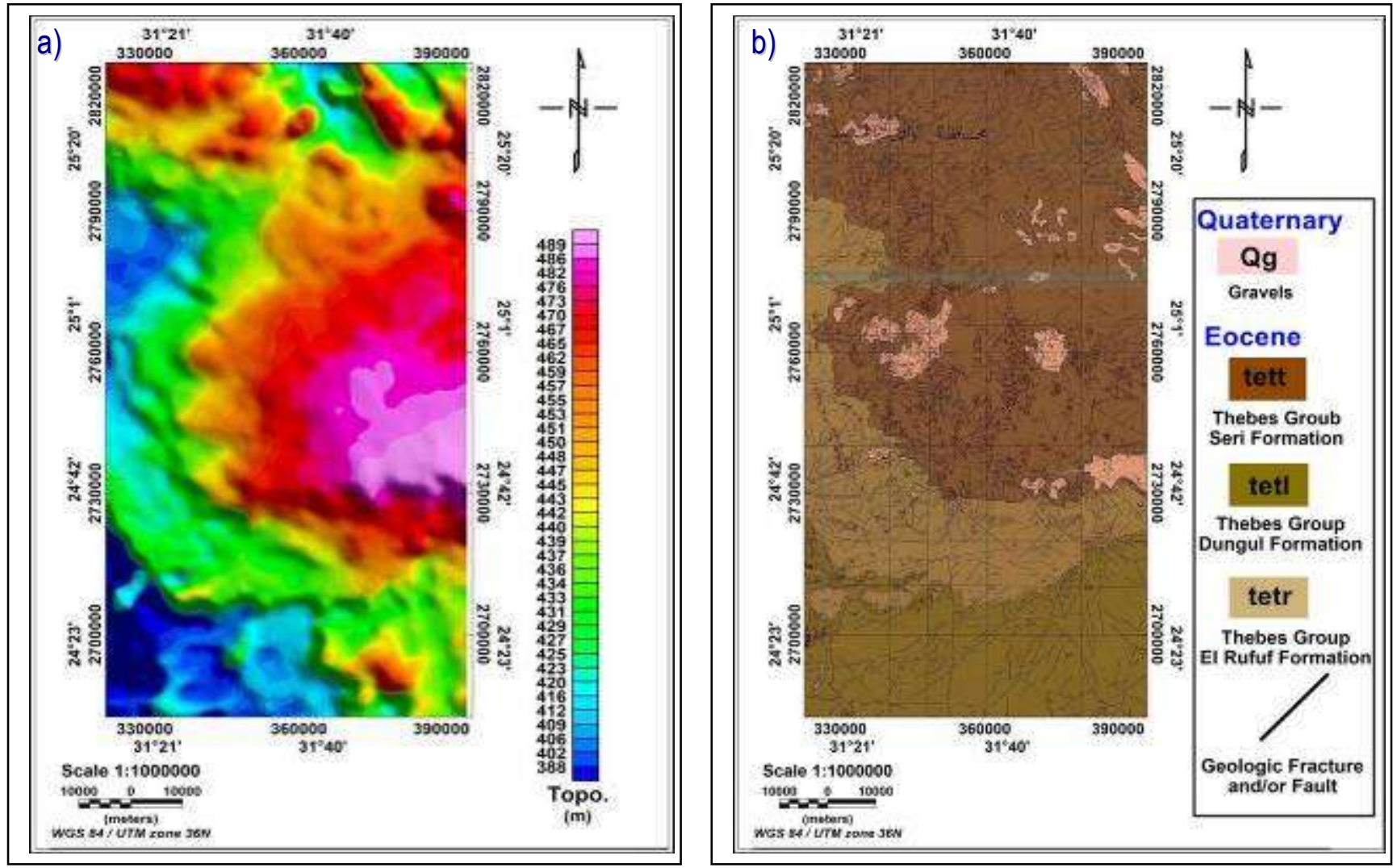

Figure 2: Regional a) topographic relief and b) outcropped geology (modified after Conoco, 1987) maps of the West-of-Edfu Region within the southern Egyptian western desert. 


\section{Airborne Total Magnetic Intensity Data}

A high-resolution airborne magnetic survey was conducted at the West-of-Edfu region, southern Egyptian western desert, by the Airborne Geophysics Department, Exploration Division, Nuclear Materials Authority (NMA) of Egypt between October and November, 2011. The used aircraft was the twin-engine turboprop King Air B200SE civil aircraft (Beechcraft Corp., USA) which is equipped with a computer-based multi-sensor airborne geophysical information system (AGIS), including continuous radar-barometric altimeter, video camera and GPS navigation recording system. The aeromagnetic data were collected using the MMS-4 airborne cesium magnetometer (Scintrex Inc., USA) with an in-flight effective recording resolution of about $0.001 \mathrm{nT}$ and sampling rate of about $0.1 \mathrm{sec}$. (equivalent to about 7.0 surveyed meters) at a mean terrain clearance of about $100 \mathrm{~m}$. The survey pattern formed almost a rectangle of an area of 9,860 $\mathrm{km} 2$. The flight-lines were oriented in NE-SW direction at $4 \mathrm{~km}$ spacing, while the tie-lines were oriented in NW-SE direction using $10 \mathrm{~km}$ spacing to meet the pre-defined main geological strike of the study area. The SM-4 SmartMag cesium magnetometer (Scintrex Inc., USA) was setup within the survey area and used as a fixed base-station for digitally monitoring and recording the geomagnetic diurnal and other time-varying fields with a ground effective recording resolution of about $0.01 \mathrm{nT}$ and sampling rate of about $0.1 \mathrm{sec}$. The base-station location was chosen to be free of geomagnetic noise, away from large-scale steel objects, vehicles and electrical power lines, which could interfere with recording of the diurnal variations. Additionally, its location had a relatively low and constant geomagnetic field gradient.

The present 2D forward modeling trials were performed using GM-SYS-2/3D code (Northwest Geophysical Associates, Inc., USA) within the Oasis Montaj software (Geosoft Inc., Canada). Its forward modeling computations are based on Talwani's algorithm (Talwani et. al., 1959; Talwani and Heirtzler, 1964; Won and Bevis, 1987).

\section{Data Reduction}

The digital base-station data from the continuous monitoring was routinely used in correcting the acquired airborne Total magnetic intensity (TMI) Field data. Additionally, the data were corrected for the international (global) geomagnetic reference field (IGRF) and other space-dependent effects. The corrected TMI data of the whole region were later plotted in the form of colored contour maps (Figure 3a) which facilitates its visualization. Reducing the data to the north-magnetic pole, inverting the observed data, filtering and higher-order derivative techniques of the data can be easily applied.

\section{Data Treatment and Qualitative/Semi-qualitative Analysis}

Using the continuous spectral analysis (Fourier transform) technique, the corrected TMI data were reduced-to-the-north magnetic pole (RTP), where the measured geomagnetic field can be migrated from the measured inclination and declination to what the field would look like at the north-magnetic pole (i.e., at an inclination of 90o and a declination of 0o) (Baranov and Naudy 1964; Bhattacharyya 1965 and 1967). The RTP field can then be attributed to source geometry and/or magnetic properties. Generally, the obtained TMI contours at the study area (Figure 3a) are complex in nature. Multiple elongated, short-wavelength, moderate/high amplitude, NW-SE and NE-SW striking aeromagnetic highs were encountered with several small-scale magnetic lows in between. This can be geologically translated as a series of unconnected Precambrian basement swells and troughs dissected by NW-SE and NE-SW rooted gravity faults within such undulations, developing alternating horst-graben structures. Since the study area is located in the northern hemisphere of mid- to low-latitude, the obtained RTP anomalies (Figure 3b) were shifted northwards, with the same general trend, but with clear shapes and well-separation from their background. Their overall amplitudes were obviously increased. Afterwards, the separation of both the regional (due to shallow-seated sedimentary rocks and structures) and residual (due to deep-seated basement rocks and structures) fields was performed using the power spectral analysis of the RTP data (Figure 5). The depth-to-the-top of deep and shallow magnetic sources can statically be approximated as regional and residual geomagnetic field intensity surfaces (Figure 4a and 4b). 

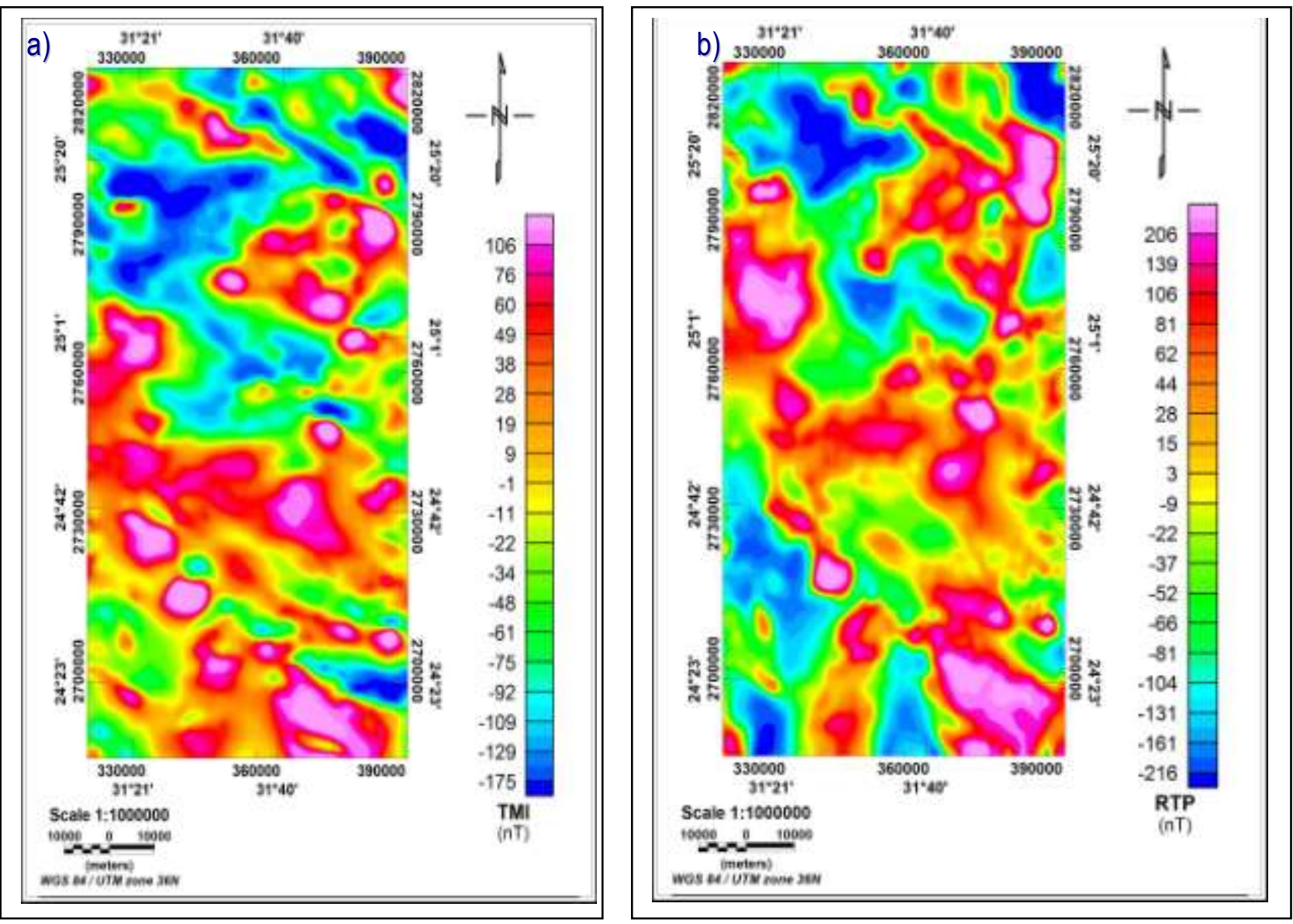

Figure 3: Observed airborne a) TMI and b) RTP contour maps at the West-of-Edfu Region within the southern Egyptian western desert.

To calculate the depth-to-the-basement, the source parameter imaging (SPI) (Thurston and Smith, 1997) (Figure 6a), analytical signal (AS) methods (Roset et. al., 1992 and Macloed., 1993) (Figure 6b) and 3D Euler deconvolution method (Thompson, 1982 and Reid, 1990) (Figure 7) were applied on the obtained RTP data. The Euler deconvolution method is insensitive to the small-scale paleomagnetic remanence intensity and/or orientation (inclination and declination angles). For the present deconvolution tryout, structural index of 0.0 , within a suitable window size of about 5 corresponding to $5 \mathrm{~km}$ and with a depth uncertainty (tolerance) of about 15\%, was critically tested and yield accurate and valid depth solutions, where the distribution and clustering of solutions along the rims of the anomalies is a good illustration of the functioning of the index value to determine location, boundary and central depth for each anomaly (Figure 7). The obtained depth values of the encountered magnetic sources were ranged between 0.9 and $4.55 \mathrm{~km}$. 

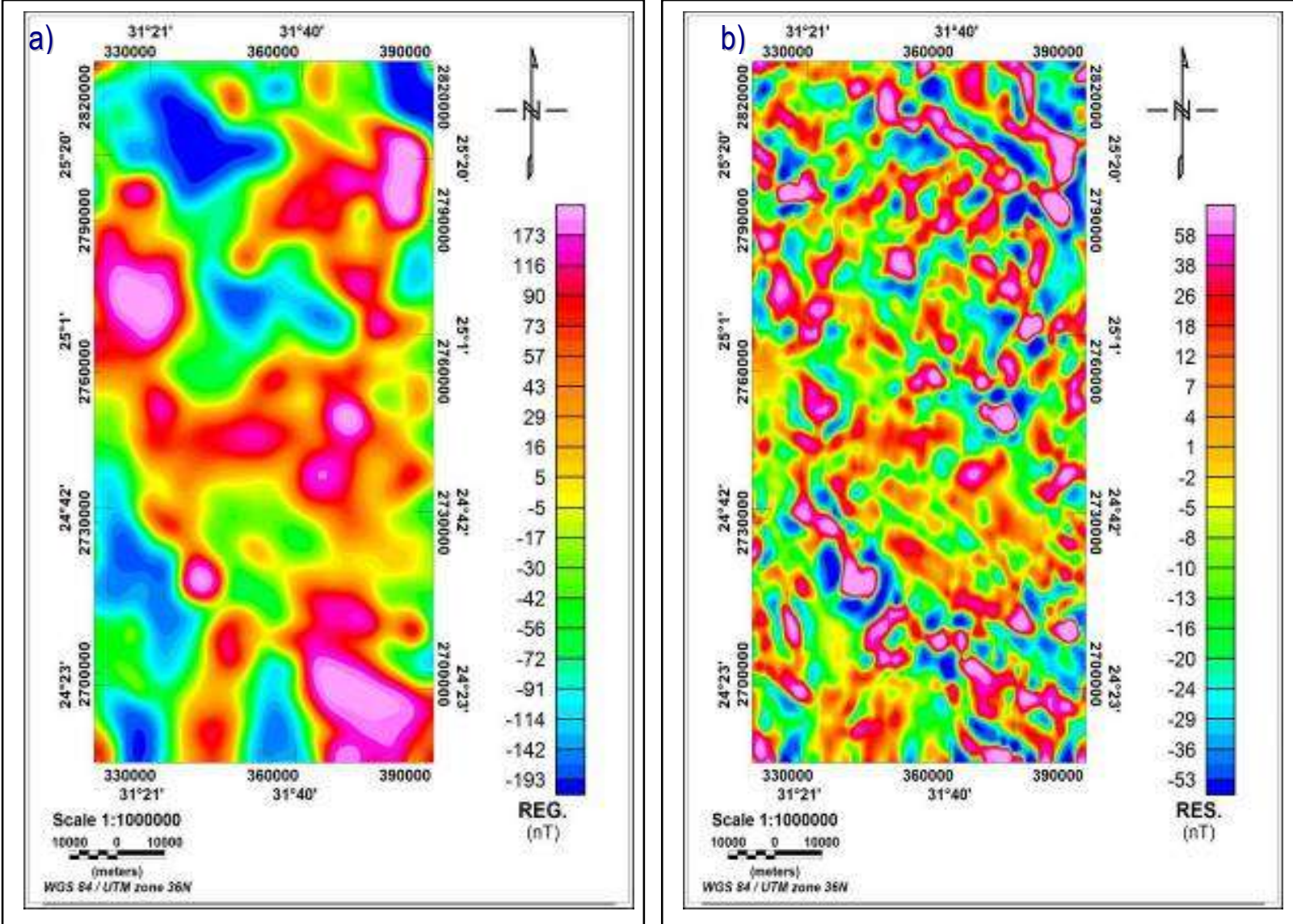

Figure 4: Estimated airborne a) regional and b) residual geomagnetic field intensity contour maps at the Westof-Edfu Region within the southern Egyptian western desert.

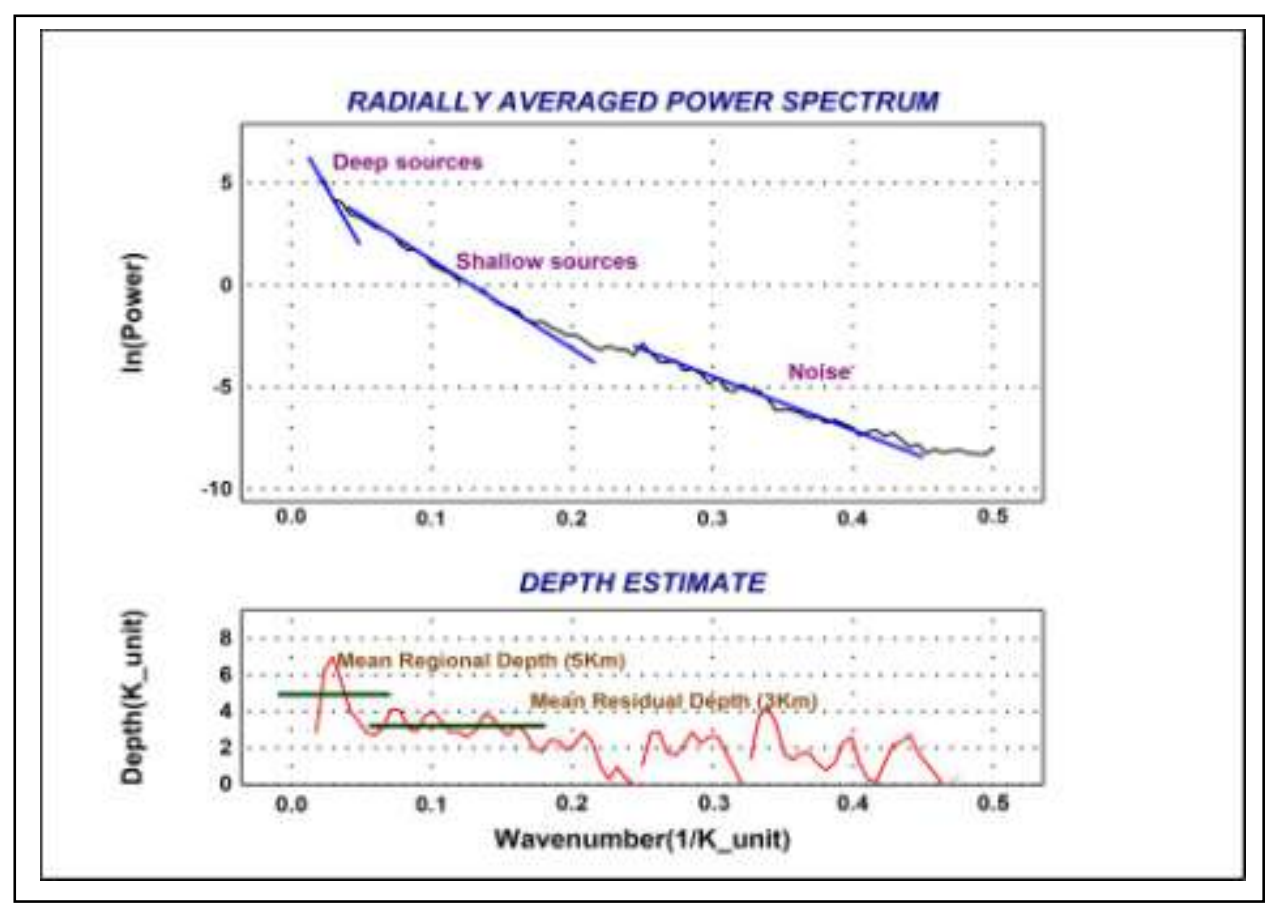

Figure 5: Power spectra of the RTP data showing the corresponding averaged depths to the magnetic anomaly source(s) at the West-of-Edfu Region within the southern Egyptian western desert. 


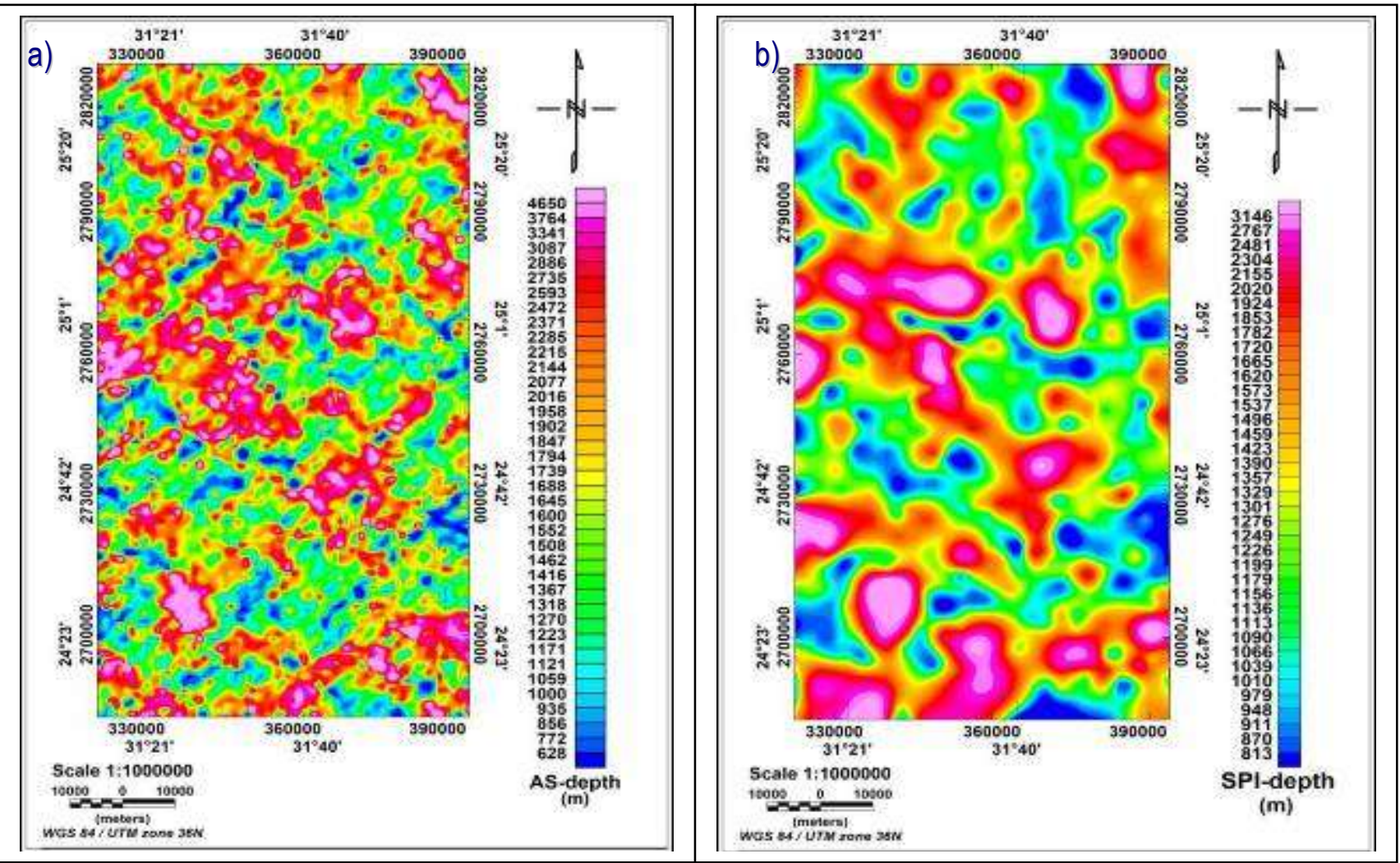

Figure 6: Calculated depth-to-the-basement anomaly contour maps from the obtained RTP data using both a) analytical signal and b) source parameter imaging techniques at the West-of-Edfu Region within the southern Egyptian western desert.

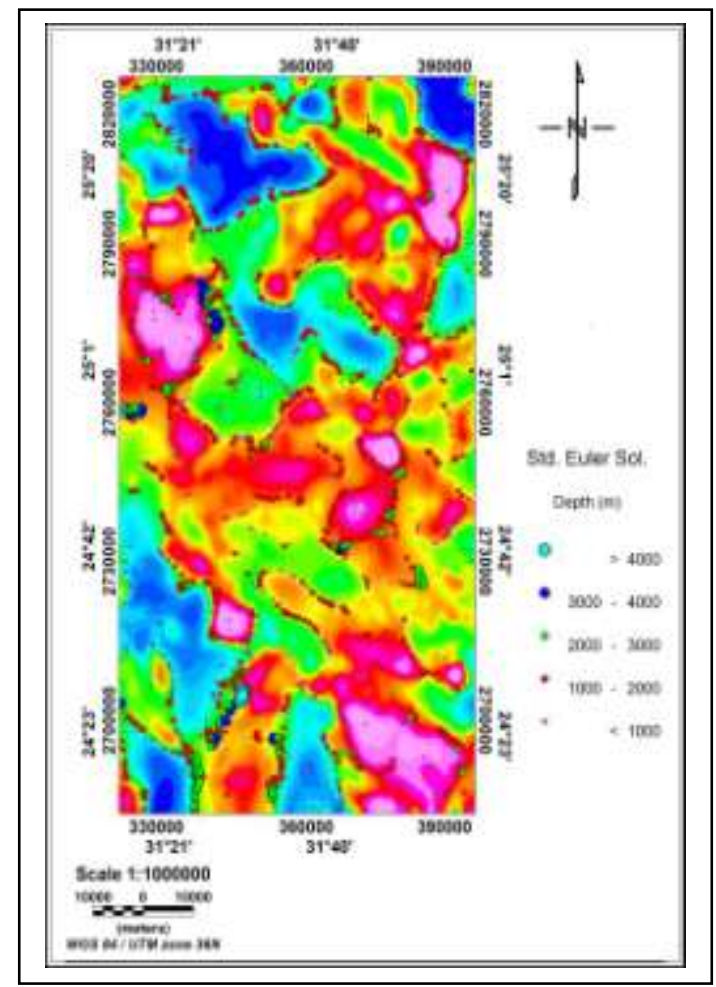

Figure 7: Standard Euler Depth solution of Structural Index SI = 0.0, depth uncertainty dz: $15 \%$ over the obtained RTP geomagnetic field intensity contour at the West-of-Edfu Region within the southern Egyptian western desert. The estimate solutions are given as colored circles. 


\section{Two-dimensional (2D) Data Inversion}

The two-dimensional (2D) inverse modeling trails were typically performed along three long RTP traverses $\mathrm{A}-\mathrm{A}^{\prime}, \mathrm{B}-\mathrm{B}^{\prime}$ and $\mathrm{C}-\mathrm{C}^{\prime}$ running in NE-SW direction, as well as one short traverse D-D' running in NW-SE direction (Figure 8). They are almost passing throughout the two available drilled stratigraphic-control wells 'WKO-1X' and 'WKO-3X' (EREX, 2006 and RISC, 2007). The present inversion trials were performed interactively using GM-SYS-2/3D code (Northwest Geophysical Associates, Inc., USA) within the Oasis Montaj software (Geosoft Inc., Canada). The inversion algorithm uses a 2D flat layered-earth model for geomagnetic response calculations. Each structural unit or block within the model extends to plus and minus infinity in the $x / y$-direction to avoid any artificial lateral magnetic effects, if present. In the absence of the small-scale paleomagnetic remanence intensity and/or orientation (inclination and declination angles) information, the natural remanent magnetization was assumed to be negligible, and induced magnetization was assumed the main for all the modeled structural unit or block (NGA, 2004).

With a manually iterated procedure, each structural unit or block were subjected to adjustable reshaping and/or magnetic susceptibility update. Subsequently, the overall calculated (synthetic) geomagnetic response of the modeled two-layered magnetic susceptibility structures, below each traverse, is statistically compared to the observed (measured) geomagnetic response to satisfy a certain RMS data misfit. Notably, the starting models for all inversion trails were initially built-up using a-priori information gained from the previously-mentioned standard qualitative and semi-qualitative interpretation results (RTP, regional and residual field intensity contour maps, and the rough depth-to-the-basement distribution maps), as well as from the available geologically reasonable information derived from the two drilled stratigraphic-control wells 'WKO-1X' and 'WKO-3X'.

The calculated responses fit the observed geomagnetic data, along the traverses A-A', B-B', C-C' and D-D', better than 3.698, 1.738, 2.913 and 1.066 RMS\%, respectively. The encountered shallow-seated sedimentary cover showed an averaged magnetic susceptibility of about 0.00038 SI, while the deep-seated basement complex showed up with a basic nature of an averaged susceptibility of about 0.089 SI. An average susceptibility value for basement surface could not fit well between observed and calculated curves which implies that there might be lateral variation in basement susceptibility consequently some bodies with varied susceptibility values are intruded to the basement layer in 2D profiles A-A', B-B' and D-D' so that better fit is obtained

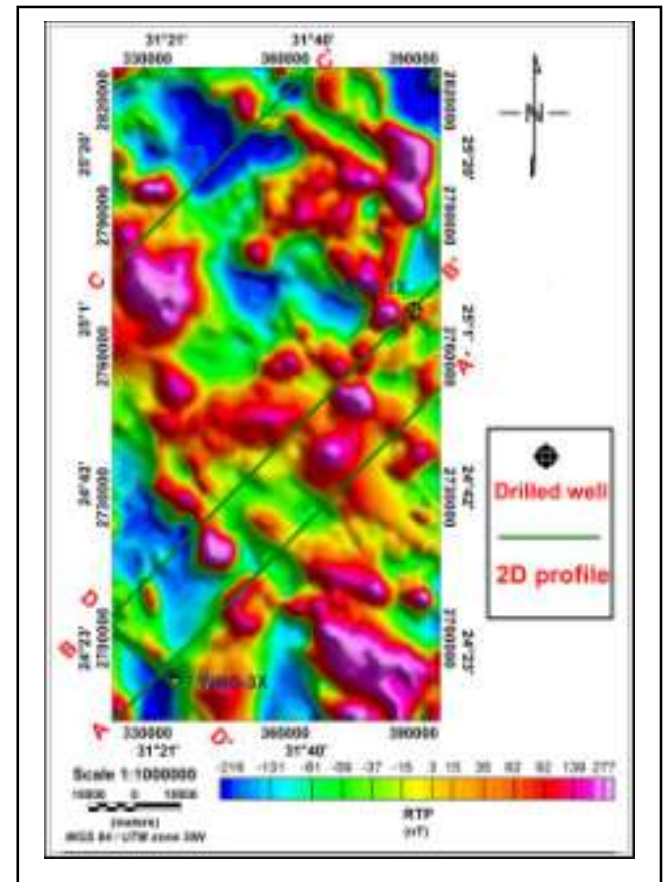

Figure 8: Locations of the traverses used for the present 2D modelling and the available two drilled stratigraphic-control wells ' $\mathrm{WKO}-1 \mathrm{X}^{\prime}$ ' and ' $\mathrm{WKO}-3 \mathrm{X}$ ', which were used wisely to correlate the interactive inversion results, laid over the RTP contour map of the West-of-Edfu Region within the southern Egyptian western desert. 


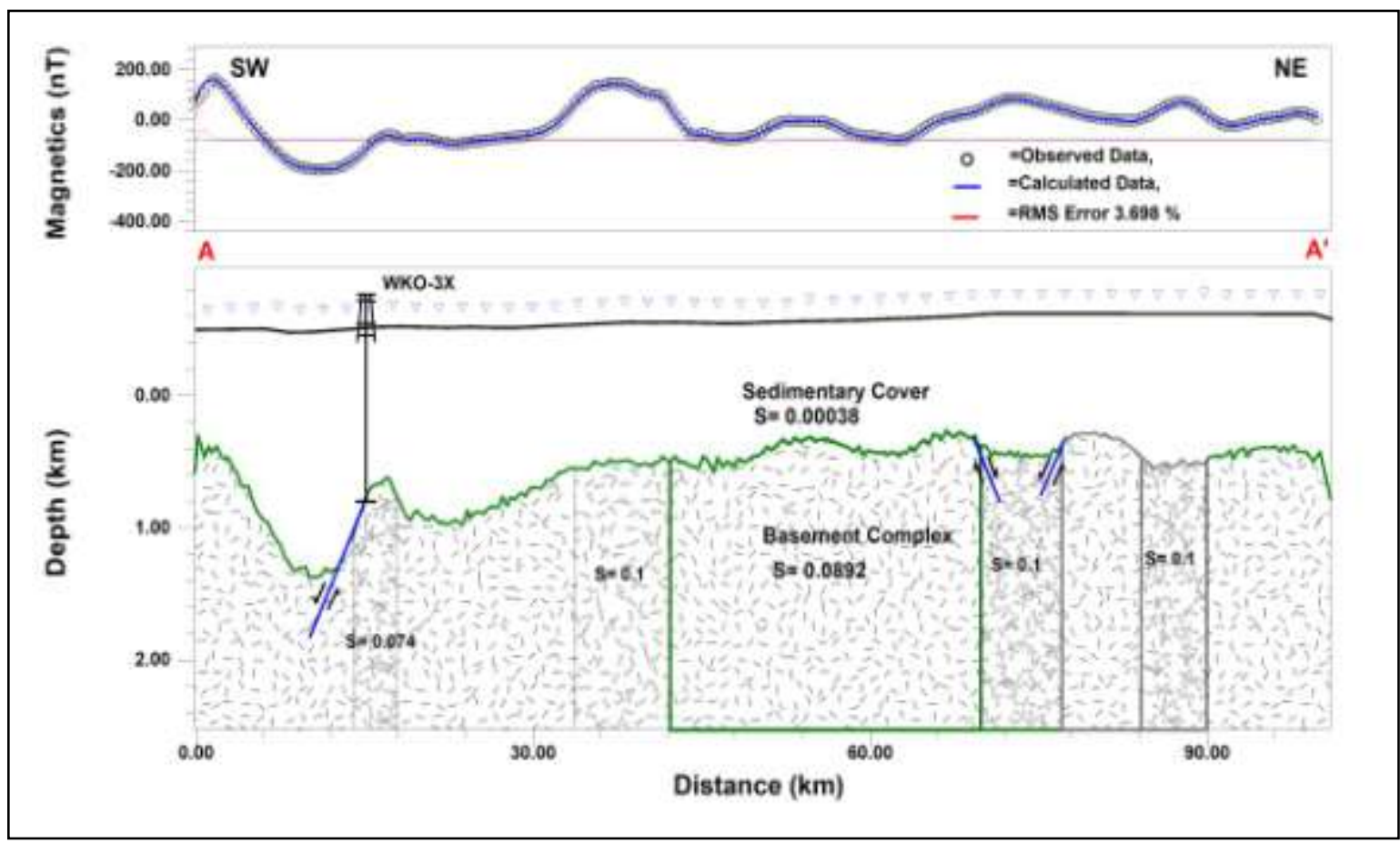

Figure 9: The 2D inverted susceptibility layered-earth model and calculated geomagnetic response below the long RTP traverse A-A'. Location of the available drilled stratigraphic-control well 'WKO-3X', which was used wisely to constrain the interactive inversion results, is donated.

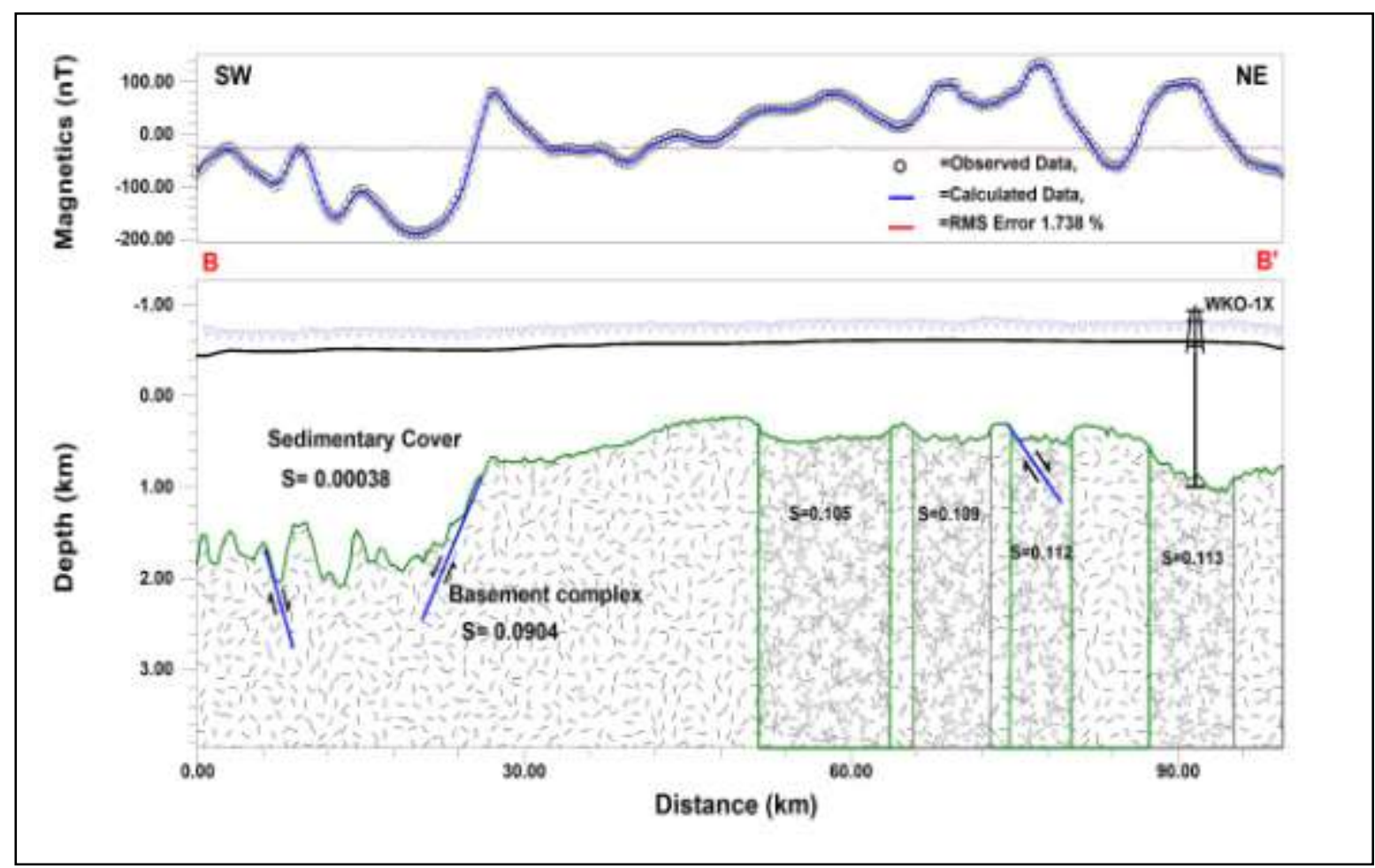

Figure 10: The 2D inverted susceptibility layered-earth model and calculated geomagnetic response below the long RTP traverse B-B'. Location of the available drilled stratigraphic-control well 'WKO-1X', which was used wisely to constrain the interactive inversion results, is donated. 


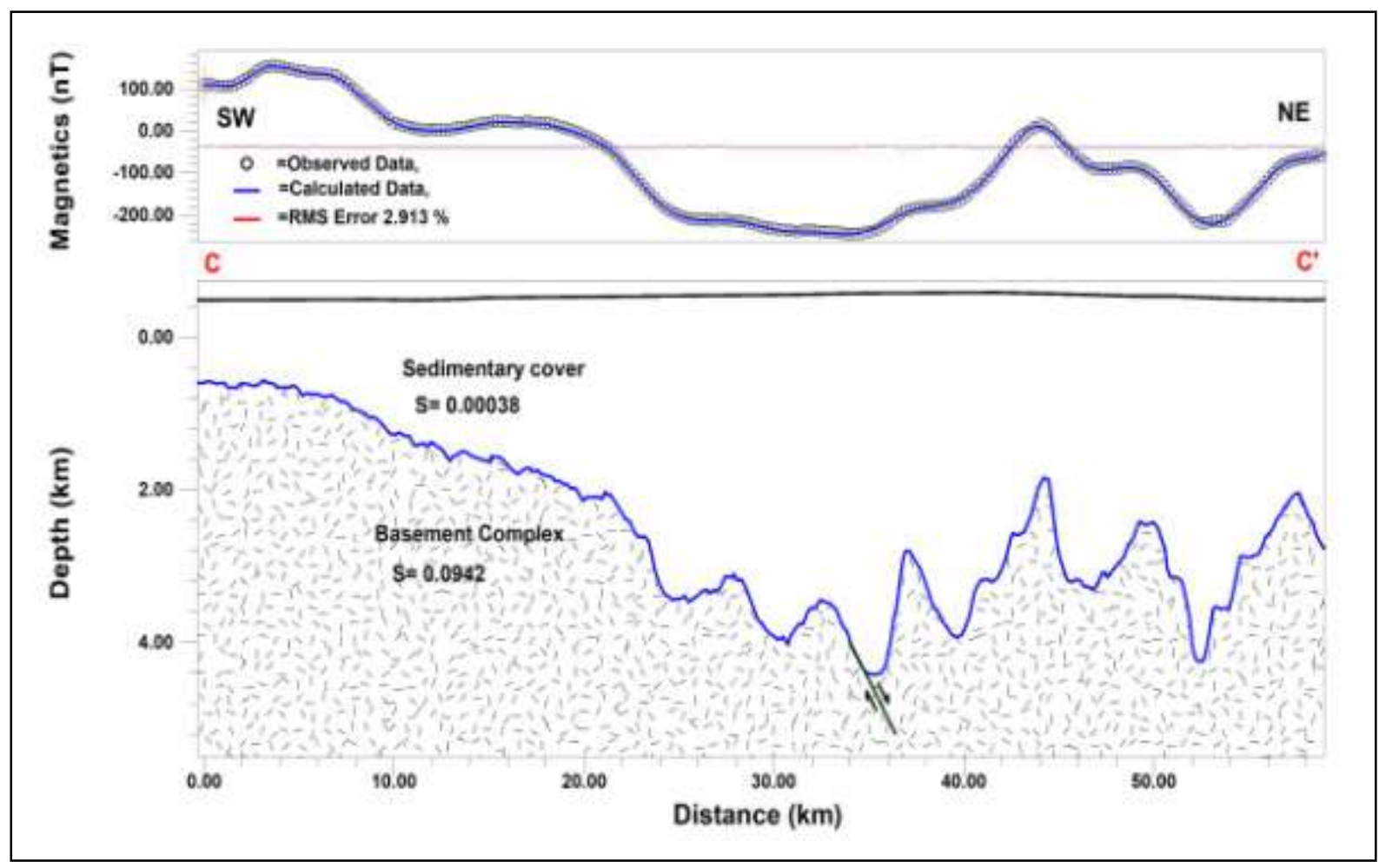

Figure 11: The 2D inverted susceptibility layered-earth model and calculated geomagnetic response below the long RTP traverse $\mathrm{C}-\mathrm{C}^{\prime}$.

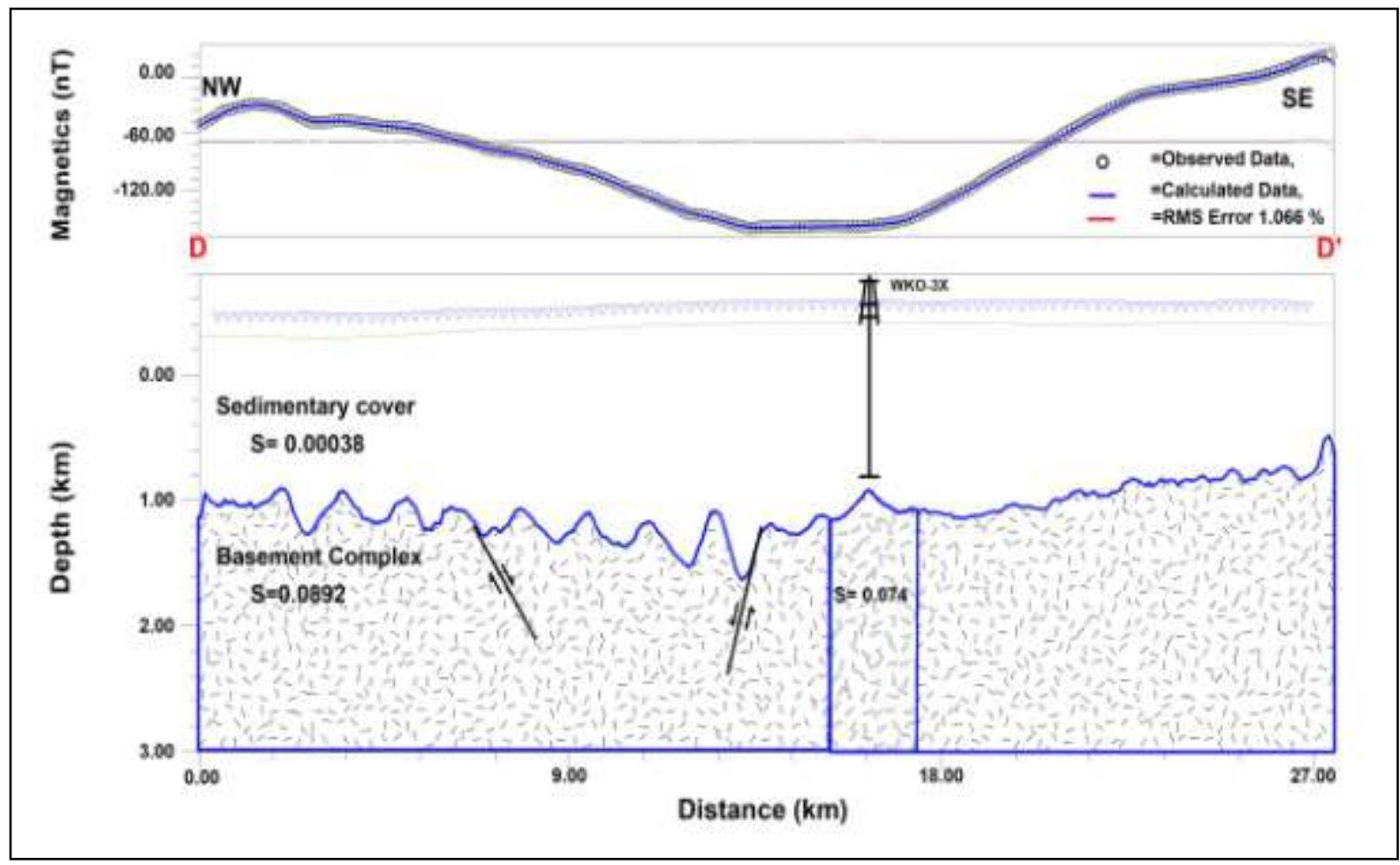

Figure 12: The 2D inverted susceptibility layered-earth model and calculated geomagnetic response below the short RTP traverse D-D'. Location of the available drilled stratigraphic-control well 'WKO-3X', which was used wisely to constrain the interactive inversion results, is donated. 


\section{Three-dimensional (3D) Data Inversion}

Spectral 3D layered-earth inversion of RTP data using Oldenburg's scheme (IEEE, 1967; Parker, 1973; Oldenburg, 1974; Pilkington and Crossley, 1986), based on Parker's forward Green's function calculation (Parker, 1973), is one of the quantitative interpretation techniques that can reduce the nonuniqueness of the 3D layered-earth magnetic susceptibility model. This is because it sets presumed sedimentary section-basement complex susceptibility contrast $\Delta \mathrm{k}$ to be laterally fixed over an index grid or voxel in $\mathrm{x}-\mathrm{y}$ template, to detect the effect of the basement topography $\mathrm{z}$ on the geomagnetic anomaly data. Because computations within the inversion scheme involve primarily the sum of the Fourier transforms of powers of the perturbing basement topography which can be computed very quickly, this technique can easily accommodate large numbers of model points without greatly decreasing the numerical stability or greatly increasing the computation. Throughout, the geomagnetic anomaly data can be inverted directly by minimizing a properly designed objective function of a minimally structured susceptibility model subject to fitting the observations. The objective function has the ability to incorporate all available a-prior information into the inversion from previous geological and geophysical knowledge about the susceptibility contrast or from the interpreter's understanding about the geological setting and its relation to susceptibility.

Using GM-SYS 3D inversion code, the presumed sedimentary section-basement complex magnetic susceptibility contrast $\Delta \mathrm{k}$ for several inversion trials was gradually set between 0.0498 and 0.0875 SI and kept fixed laterally during the inversion run. Latter, the inverted basement relief images, corresponding to the used susceptibility contrasts, were consistently inspected. The effective susceptibility contrast was found very close to susceptibility contrast of 0.0875 SI, and correspondingly its calculated basement relief image (Figure 13a) is an optimal therefore. The overall calculated 3D response fit the observed geomagnetic data with mean misfit range $\pm 50.0 \mathrm{nT}$ (Figures13b).

The inverted depth-to-the-basement estimates were reliably varied between 0.13 and $2.57 \mathrm{~km}$, from the existing averaged ground surface, and correlated well with the two available drilled stratigraphic-control wells 'WKO-1X' and 'WKO-3X'. The encountered basement relief at the study area was shown up with two major basinal structures. The deepest basin is located at the southwestern part of the area, while the relativity shallower basin is located in the northwestern-north part of the area. The modeled NW-SE and NE-SW trending fault blocks structurally control such two basins.
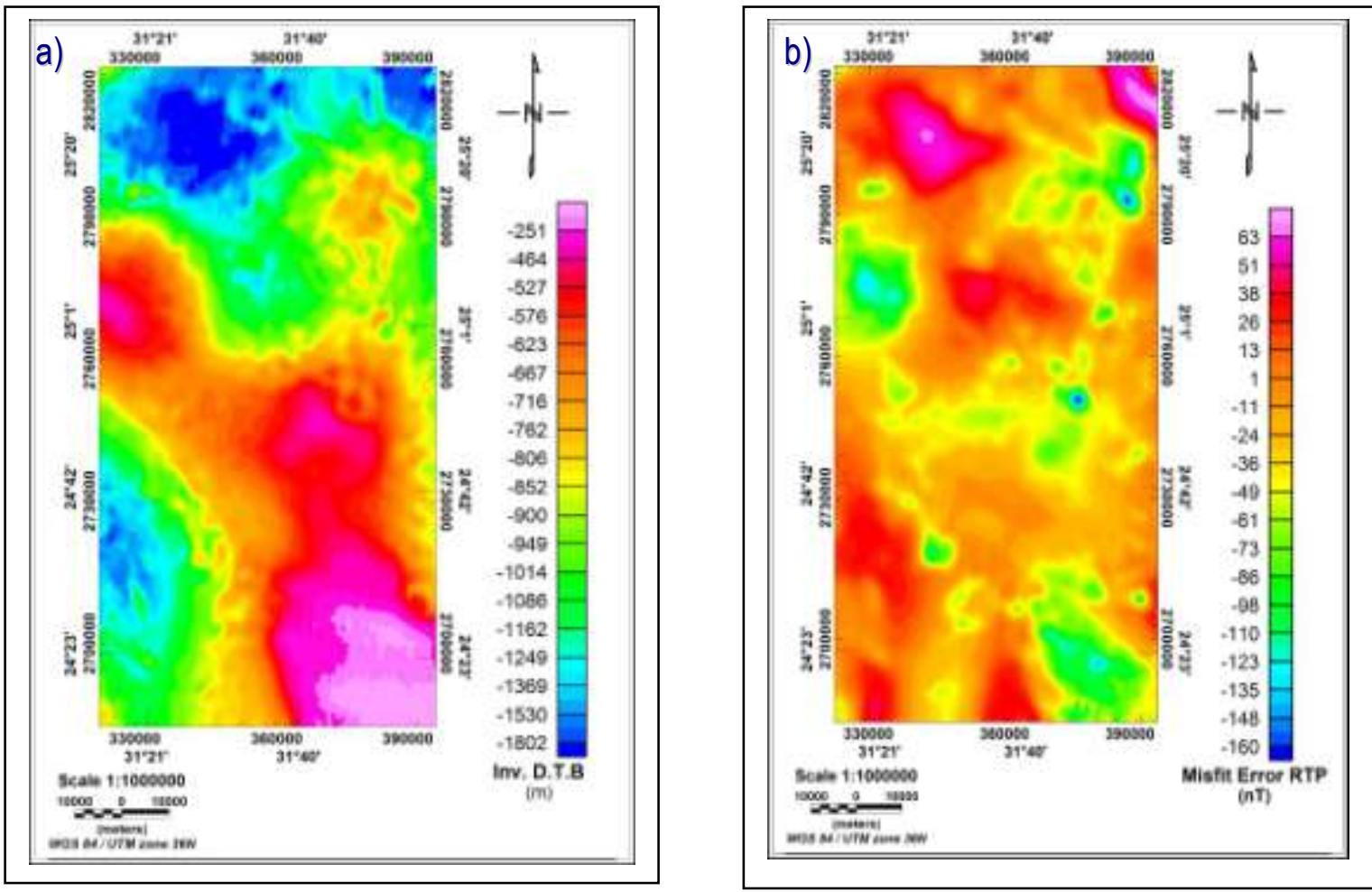

Figure 13: a) Basement relief contour map upon performing the 3D layered-earth inversion of the subsurface magnetic susceptibility distributions and $b$ ) the areal data misfit between the observed and calculated RTP data. 

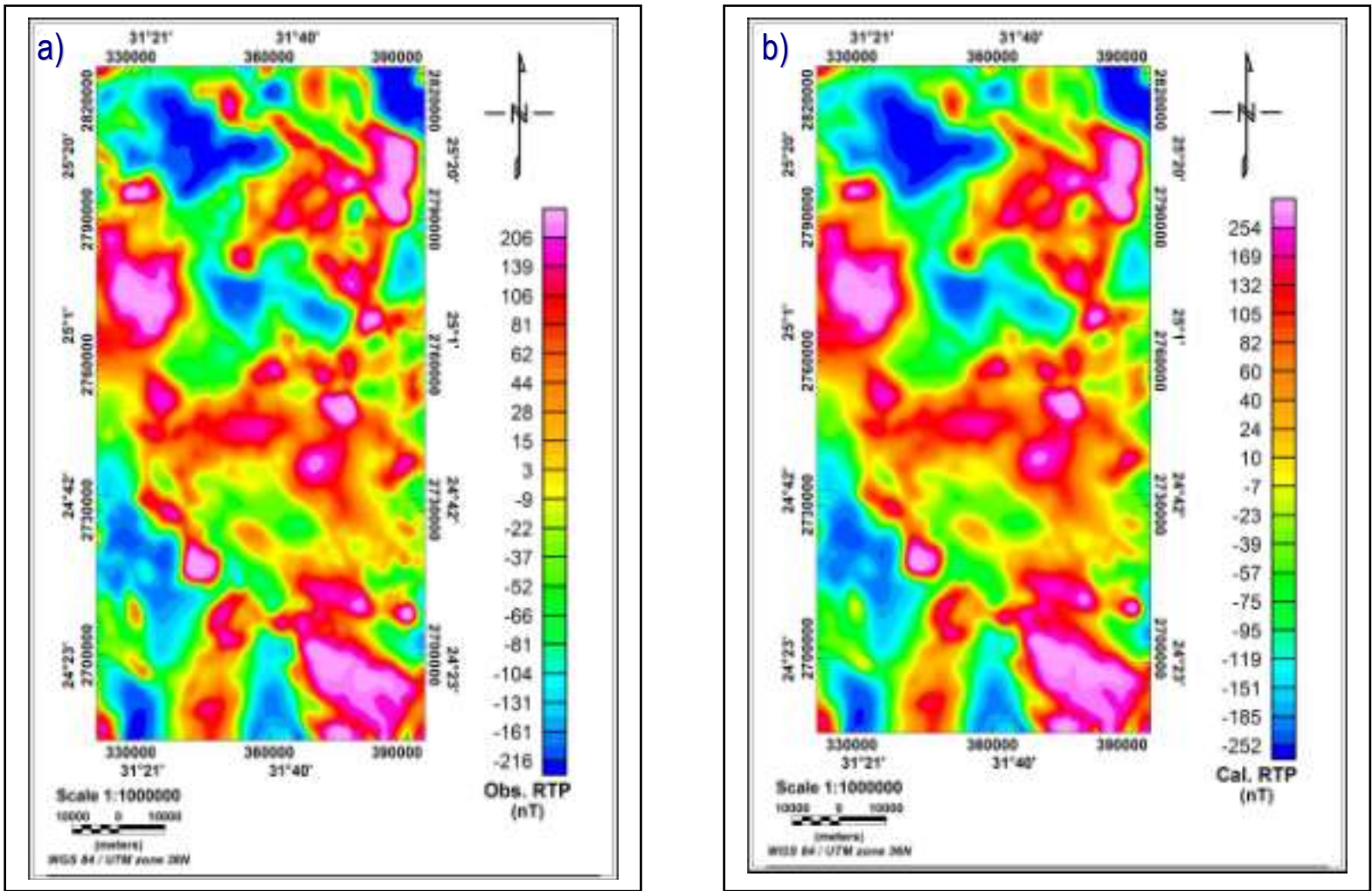

Figure 14: a) Observed and b) calculated RTP contour maps upon performing the 3D layered-earth inversion of the subsurface magnetic susceptibility distributions.

\section{Concluding Remarks}

High-resolution airborne geomagnetic anomaly data sets were consistently and extensively acquired, processed and multi-dimensionally inverted over the West-of-Edfu region, within the southern Egyptian western desert, to accurately image the deep-seated basement structures and configuration. The starting models for all inversion trails were initially built-up using a-priori information gained from the progressive standard qualitative and semi-qualitative interpretation results. The inverted susceptibility models not only fit the anomaly data reasonably, but also have a realistic likelihood of representing the earth geology. The expected basement rock types can be classified, according to their average magnetic susceptibility, as plutonic igneous rocks of acidic composition (granites together with granodiorites and dacites). The encountered deep-seated Precambrian basement structures are generally trending NW-SE and NE-SW directions. The depth-to-the-basement estimates were reliably varied between 0.13 and $2.57 \mathrm{~km}$, from the existing averaged ground surface, and correlated well with the available drilled stratigraphic-control wells. Additionally, the results suggested that the sedimentary cover is tectonically affected by such deep-seated basement structures with a set of tectonic faults extending from the basement upwards through the sedimentary cover. These faulted sedimentary blocks may constitute potential structural traps for the hydrocarbon accumulation; therefore further geophysical investigation could be needed. 


\section{References}

[1]. Abd El-Razik, T. and Razavaliaev, A., 1972. On the tectonic origin of the Nile Valley between Idfu and Qena. Egyptian Journal of Geology, 16(2), 235-245.

[2]. Attia, M.I., 1954. Deposits in the Nile Valley and the Delta. Geological Survey of Egypt-Egyptian Ministry of Commerce and Mines, Quarries Department, Cairo, Egypt. Internal Report, 1-356.

[3]. Baranov, B. and Naudy, H., 1964. Numerical Calculation of the Formula of Reduction to the Magnetic Pole. Geophysics, 29(1), 67-79.

[4]. Barbosa, V.C.F., Silva, J.B.C. and Medeiros, W.E., 1999. Stability analysis and improvement of structural index estimation in Euler deconvolution, Geophysics, 64, 48-60.

[5]. Bhattacharyya, B.K., 1965. Two-dimensional harmonic analysis as a tool for magnetic interpretation. Geophysics, 30, 829-857.

[6]. Bhattacharyya, B.K., 1967. Some general properties of potential fields in space and frequency domain: A review. Geoexploration, 5, 127-143.

[7]. Bott, M.H.P., 1960. The use of Rapid Digital Computing Methods for Direct Gravity Interpretation of Sedimentary Basins. Geophysical Journal of the Royal Astronomical Society, 3(1), 63-67.

[8]. CONOCO Coral Inc. and Egyptian General Petroleum Corporation (EGPC), 1987. Geologic Map of Egypt, Sheet No. 3, West Edfu, Scale 1: 500,000. Cairo, Egypt.

[9]. Corbató, C.E., 1965, A least-squares procedure for gravity interpretation. Geophysics, 30, $228-233$.

[10]. Danes, Z. F., 1960. On a Successive Approximation Method for Interpreting Gravity Anomalies. Geophysics, 25(6), $1215-1228$.

[11]. Earth Resources Exploration (EREX) and Centurion Petroleum Corporation, 2006. Surface Geology of Upper Egypt: Integrated Study of Wadi Kharit, Atmour El-Nuqra, Qena Bend, Kom Ombo and South Abu Tartur. Internal Report, Cairo, Egypt, 1-387.

[12]. FAO (Food and Agriculture Organization of United Nations) / UNDP (United Nations Development Program), 1966. High Dam Soil Survey-United Arab Republic. FAO Land and Water Development Division-Ministry of Agriculture, Cairo, Egypt. Volume II: The Reconnaissance Soil Survey Report (LA-SF 16/UAR), 473 P.

[13]. I.E.E.E. Trans., 1967. Special issue on Fast Fourier transform and its application to digital filtering and spectral analysis. Audio Electroacoustics, AU-15, 43-117.

[14]. Issawi, B,1983. Ancient Rivers of the Eastern Egyptian Desert. Episodes, 2, 3-6.

[15]. Issawi, B., and Osman, R. A., 1993. Tectono- sedimentary synthesis of the Paleozoic- Cretaceous clastics, southwest Aswan, Egypt. Sedimentol. Egypt, 1, 11-21.

[16]. Koch, M., Gaber A., Burkholder B. and Geriesh, M.H., 2012. Development of New Water Resources in Egypt with Earth Observation data: Opportunities and Challenges. International Journal of Environment and Sustainability, 1(3), 1-11.

[17]. Lines, L. R. and Treitel, S., 1984. Tutorial: A review of least-squares inversion and its application to Geophysical problems. Geophysical Prospecting, 32, 159-186.

[18]. Macleod, I. N., Vierra, S. And Chaves, A. C., 1993. Analytic signal and reduction-to-the-pole in the interpretation of total magnetic field data at low magnetic latitudes, Proceedings of the third international congress of the Brazilian society of geophysicists.

[19]. Marquardt, D. W., 1963. An algorithm for least-squares estimation of non-linear parameters. SIAM J., 11, 431-441.

[20]. Northwest Geophysical Associates (NGA), Inc., 2004. GM-SYS Gravity/Magnetic Modeling Software, User's Guide, Version 4.9, 1-101.

[21]. Oldenburg, D. W., 1974. The inversion and interpretation of gravity anomalies. Geophysics, 39, 424-438.

[22]. Parker, R. L., 1973. The rapid calculation of potential anomalies. Geophys. J. R. Astron. Soc., 31, $447-455$.

[23]. Pilkington, M. and Crossley, D. J., 1986. Determination of crustal interface topography from potential fields Geophysics, 51, 1277-1284

[24]. Reid, A.B., Allsop, J.M., Granser, H., Millet, A.J. and Somerton, I.W., 1990. Magnetic interpretation in three dimensions using Euler deconvolution. Geophysics, 55, 80-91.

[25]. Resource Investment Strategy Consultants (RISC), 2007. Independent Technical Review of Certain Exploration Assets in USA and Egypt for Sky Energy Investment Ltd. (SEI)-Karl Thomson Energy Ltd. (KTE). Internal Report, West Perth, Western Australia, 1-37. (URL: http://www.hoifuenergy.com/eng/2007/en_ann20070630-111.pdf).

[26]. Roest, W.E., Verhoef, J. and Pilkington M., 1992. Magnetic interpretation using 3-D analytic signal. Geophysics, 57, $116-125$.

[27]. Said, R., 1962. The Geology of Egypt. Elsevier, Amsterdam and New York.

[28]. Salman, A.B., 1974. Structural and radioactivity of some phosphate deposits, East Luxor area, Egypt. Ph.D. Thesis, Ain Shams University, Cairo, Egypt.

[29]. Tanner J.G. 1967. An automated method of gravity interpretation. Geophysical Journal of the Royal Astronomical Society, 13, 339-347

[30]. Thompson, D. T., 1982. EULDPH: A new technique for making computer-assisted depth estimates from magnetic data. Geophysics, 47, 31-37.

[31]. Thurston, J.B., and Smith, R. S., 1997. Automatic conversion of magnetic data to depth, dip, and susceptibility contrast using the SPI(TM) method. Geophysics, 62, 807-813.

[32]. Webring, M.W., 1985. SAKI: A Fortran program for generalized linear inversion of gravity and magnetic profiles. U.S. Geological Survey Open File Report, 29, 85-122.

[33]. Won, I.J. and Bevis, M.G., 1987. Computing the gravitational and magnetic anomalies due to a polygon: Algorithms and Fortran subroutines. Geophysics, 52, 232-238.

[34]. Youssef, M.I., 1968. Structural pattern of Egypt and its interpretation. American Association of Petroleum Geologists Bulletin, 52(4), 601-614. 